\title{
Backstepping Control of Rewinding Systems with Flexible Couplings
}

\author{
Thi Ly Tong ${ }^{1,2}$, Hiep Binh Nguyen ${ }^{1}$, Duc Thanh Cao ${ }^{1}$, Tung Lam Nguyen ${ }^{1, *}$ \\ ${ }^{1}$ School of Electrical Engineering, Hanoi University of Science and Technology, Vietnam \\ ${ }^{2}$ Faculty of Electrical Engineering Technology, Hanoi University of Industry, Vietnam
}

Received February 10, 2020; Revised April 3, 2020; Accepted April 27, 2020

Copyright $\mathrm{C} 2020$ by authors, all rights reserved. Authors agree that this article remains permanently open access under the terms of the Creative Commons Attribution License 4.0 International License

\begin{abstract}
Roll-to-roll (R2R) system can be found and applied in various fields, such as paper manufacture and printing process. The matter regarding tension control is still a challenge because this tends to rely on elasticity of web materials with its elasticity and roll inertia which change. Additionally, another issue is limited stiffness shafts connecting the web handling system and driving motor. Due to non-rigid nature of the shafts, un-wanted vibration can be released, and this impact to the system. Therefore, the tension control is more complicated. In this paper, a control solution for a roll-to-roll web-transport system with flexible couplings will be performed. The connection of this system coupled with motors through non-rigid driving shaft is formed as a two-mass system. Moreover, the paper shows that the thickness of web material is assumed to be conscious in order to achieve a simple calculation of roll inertia momentum. By using backstepping control technique, control laws for unwinding and rewinding roll are defined. The control schemes ensure a linear velocity and tension tracking performance of the system. Extensive numerical simulations are carried out to verify the feasibility of the proposed control strategy. The simulation results indicate the effectiveness of the proposed control, web tension and position are driven to desired values.
\end{abstract}

Keywords Backstepping, Flexible Couplings, Roll-to-roll System, Two Mass System

\section{Introduction}

Roll-to-roll processing, or R2R, is a fabrication method used in manufacturing that embeds, coats, prints or laminates varying applications onto a flexible rolled substrate material [1], [2], and [3] . The material is a substrate-based manufacturing technology involving continuous processing of a flexible and extensible substrate (web) as it is transferred from one roller on to another [4]. General structure of system contains two main parts which are an unwinder and a rewinder [5]. For R2R structure, the control of web tension and web transport velocity are vitally important and needs to be taken into account [6]. In order to create a suitable controller for this system, a mathematical model and a proper control need to be obtained.

Tension control is essential in web-handling systems. Low tension lead to web winkle and non-compact rewinding web roll. Meanwhile, over-tension cause web breakage resulting in serious production efficiency and financial problems. Classical PID control is widely used in tension regulation [7] and [8], however the approach presents several drawbacks in dealing with nonlinear systems with varying parameters such as the web-handling system. Nonideal effects on web tension were studied, based on the models developed, methods for the control of tension. Recently, many researchers have focused on the control law for this drive system [9] and [10]. One of typical control laws based on back-stepping technique for R2R systems is proposed in [11] and [12].

A number of new ideas, approaches, and results have been extensively developed during the past few years related to nonlinear models have been employed for R2R systems [13]-[15] however, a wide range of system nonlinearities are ignored [16] and [17]. Normally, the shaft connecting a drive motor and a load machine is considered to be rigid when designing the industrial drive of R2R system [18]-[20]. This omission is acceptable in case of the small roll inertia and the short shaft, but not in the cases that characteristics of mechanical parts are considered. In fact, a torsional vibration is often generated when the motor and roll are connected with the flexible shaft. Neglecting shaft elasticity in control designs might lead to dramatic oscillations [21] and [22]. As a result, the stability of the R2R systems will be affected or the 
mechanical coupling between the driven and loading machine could be destroyed.

The work aims at developing a model of the R2R web-transport system with flexible couplings. The obtained mathematical model used to design the control law for web position in a comprehensive procedure. Based on the backstepping method, this paper shows a simple approach that can be separately applied to the unwinder and rewinder.

\section{Dynamics of R2r System with Flexible Couplings}

As shown in Fig. 1, a typical structure of R2R system contains an unwinder, a rewinder, a load cell subsystem with idle rollers and two dancer subsystems.

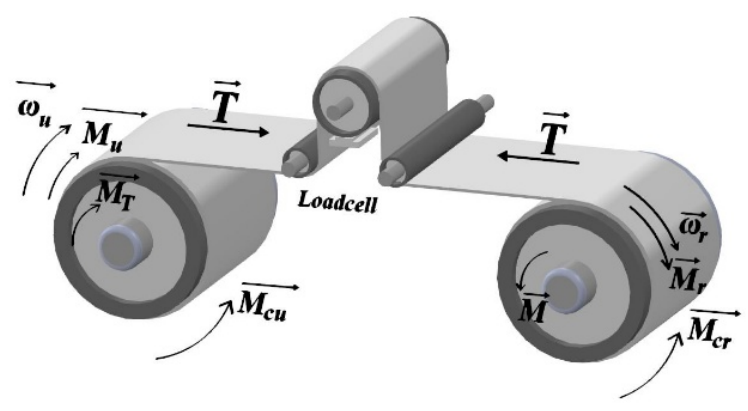

Figure 1. Structure of rewinding system

The idle rollers guide the moving web around the load cell in a fixed angle. The unwinder and rewinder are controlled with the different motors. By controlling $M_{u}$ and $M_{r}$ applied to the unwind and rewind rolls, the web tension, angular velocity and rotational angular of the system can be controlled. By applying Newton's law and the principle of mass conservation [5], the non-linear dynamic equations of rewinding system can be given as follows:

$$
\begin{gathered}
\dot{\omega}_{u}=\frac{1}{J_{u}} M_{u}+\frac{R_{u}}{J_{u}} T-\frac{c_{u}}{J_{u}} \omega_{u} \\
\dot{\omega}_{r}=\frac{1}{J_{r}} M_{r}-\frac{R_{r}}{J_{r}} T-\frac{c_{r}}{J_{r}} \omega_{r} \\
\dot{T}=\frac{(T+E S) R_{r}}{L} \omega_{r}-\frac{(2 T+E S) R_{u}}{L} \omega_{u}
\end{gathered}
$$

Where angular velocities and radiuses are calculated by the following equations:

$$
\begin{aligned}
\theta_{u} & =\int_{0}^{t} \omega_{u} \\
\theta_{r} & =\int_{0}^{t} \omega_{r}
\end{aligned}
$$

$$
\begin{gathered}
R_{u}=R_{u 0}-h \frac{\theta_{u}}{2 \pi} \\
J_{u}=J_{u 0}+\pi \rho \\
J_{u}=J_{u 0}+\pi \rho \omega \frac{\left(R_{u}{ }^{4}-R_{u 0}{ }^{4}\right)}{4} \\
J_{r}=J_{u r}+\pi \rho \omega \frac{\left(R_{r}{ }^{4}-R_{r 0}{ }^{4}\right)}{4}
\end{gathered}
$$

\begin{tabular}{|c|c|c|}
\hline \multicolumn{2}{|c|}{ Parameters } & \multirow{2}{*}{$\begin{array}{l}\text { Units } \\
\mathrm{m}\end{array}$} \\
\hline$R_{u}$ & Operating radius of the unwind roll & \\
\hline$R_{u 0}$ & Initial radius of the unwind roll & $\mathrm{m}$ \\
\hline$R_{r}$ & Operating radius of the rewind roll & $\mathrm{m}$ \\
\hline$R_{r 0}$ & Initial radius of the rewind roll & $\mathrm{m}$ \\
\hline$J_{u}$ & Total moment of inertia of the unwind roll & $\mathrm{kgm}^{2}$ \\
\hline$J_{u 0}$ & Initial total moment of inertia of the unwind roll & $\mathrm{kgm}^{2}$ \\
\hline$J_{r}$ & Total moment of inertia of the rewind roll & $\mathrm{kgm}^{2}$ \\
\hline$J_{r 0}$ & Initial total moment of inertia of the rewind roll & $\mathrm{kgm}^{2}$ \\
\hline$\omega_{u}$ & Angular velocity of the unwind roll & $\mathrm{rad} / \mathrm{s}$ \\
\hline$\theta_{u}$ & Rotational angular of the unwind roll & $\mathrm{rad}$ \\
\hline$\omega_{r}$ & Angular velocity of the rewind roll & $\mathrm{rad} / \mathrm{s}$ \\
\hline$\theta_{r}$ & Rotational angular of the rewind roll & $\mathrm{rad}$ \\
\hline$c_{u}$ & Coefficient of vicious friction of the unwind roll & $\mathrm{Nms}$ \\
\hline$c_{r}$ & Coefficient of vicious friction of the rewind roll & Nms \\
\hline$M_{u}$ & Torque applied to the unwind roll & $\mathrm{Nm}$ \\
\hline
\end{tabular}

Detailed explanation of the system parameters is given in Table 1 as follows

Table 1. Rewinding system parameters 


\begin{tabular}{|c|l|l|}
\hline$M_{r}$ & Torque applied to the rewind roll & $\mathrm{Nm}$ \\
\hline$T$ & Web tension & $\mathrm{N}$ \\
\hline$L$ & Total length of web & $\mathrm{m}$ \\
\hline$E$ & Elasticity of web & $\mathrm{N} / \mathrm{m}^{2}$ \\
\hline$S$ & Cross sectional area of web & $\mathrm{m}^{2}$ \\
\hline$h$ & The thickness of web & $\mathrm{m}$ \\
\hline$w$ & The width of web & $\mathrm{m}$ \\
\hline$\rho$ & The density of web & $\mathrm{kg} / \mathrm{m}^{3}$ \\
\hline
\end{tabular}

As shows Fig. 2, a schematic of a two-mass resonant system consisting of two lumped inertias $J_{M}$ and $J$ for motor and load, respectively, which are coupled via a shaft with finite stiffness $k_{\mathrm{c}}$.

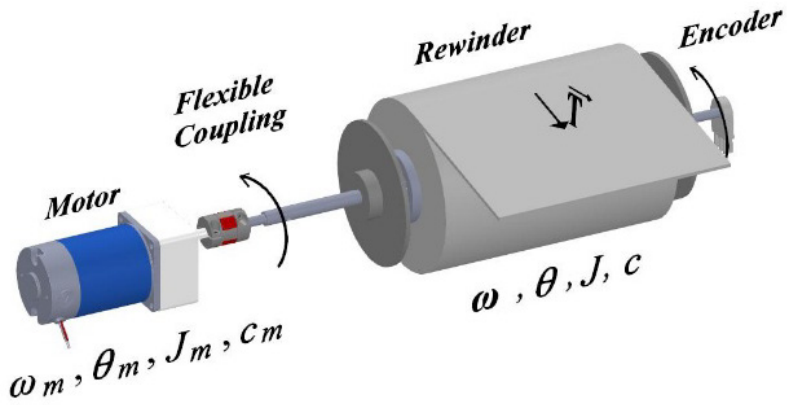

Figure 2. A R2R system with flexible coupling

Since the unwinder and rewinder are driven with different flexible coupling, the following relationships can be obtained according to (1) and (2) by applying the law of energy conservation along with the assumption of the motors are ideal torque generating actuators:

$$
\begin{gathered}
\dot{\omega}_{m u}=\frac{1}{J_{m u}} M_{m u}+\frac{1}{J_{m u}} M_{u}-\frac{c_{m u}}{J_{m u}} \omega_{m u} \\
\dot{\omega}_{m r}=\frac{1}{J m_{r}} M_{m r}-\frac{1}{J_{m r}} M_{r}-\frac{c_{m r}}{J_{m r}} \omega_{m r} \\
M_{u}=k_{s u}\left(\theta_{m u}-\theta_{u}\right)+c_{s u}\left(\omega_{m u}-\omega_{u}\right) \\
M_{r}=k_{s r}\left(\theta_{m r}-\theta_{r}\right)+c_{s r}\left(\omega_{m r}-\omega_{r}\right)
\end{gathered}
$$

\begin{tabular}{|c|c|c|}
\hline \multicolumn{2}{|c|}{ Parameters } & \multirow{2}{*}{$\begin{array}{l}\text { Units } \\
\mathrm{Nm} / \mathrm{rad}\end{array}$} \\
\hline$k_{s u}$ & Shaft stiffness of the unwind motor & \\
\hline$k_{s r}$ & Shaft stiffness of the rewind motor & $\mathrm{Nm} / \mathrm{rad}$ \\
\hline$c_{s u}$ & $\begin{array}{l}\text { Coefficient of vicious friction of the unwind } \\
\text { motor }\end{array}$ & $\mathrm{Nms} / \mathrm{rad}$ \\
\hline$c_{s r}$ & $\begin{array}{l}\text { Coefficient of vicious friction of the rewind } \\
\text { motor }\end{array}$ & $\mathrm{Nms} / \mathrm{rad}$ \\
\hline$\theta_{m u}$ & Unwind motor Rotational angular & $\mathrm{rad}$ \\
\hline$\omega_{m u}$ & Rotational angular of the rewind motor & $\operatorname{rad}$ \\
\hline$\theta_{m r}$ & Rotational angular of the rewind motor & $\mathrm{rad} / \mathrm{s}$ \\
\hline$\omega_{m r}$ & Angular velocity of the rewind motor & $\mathrm{rad} / \mathrm{s}$ \\
\hline$M_{m u}$ & $\begin{array}{l}\text { Control torque generated by the motor at } \\
\text { unwinder }\end{array}$ & $\mathrm{Nm}$ \\
\hline$M_{m r}$ & $\begin{array}{l}\text { Control torque generated by the motor at } \\
\text { rewinder }\end{array}$ & $\mathrm{Nm}$ \\
\hline
\end{tabular}

Where the system parameters are given in Table 2.
Table 2. Flexible coupling system parameters

The aforementioned problems will impact on the web tension directly. If the web tension does not meet the requirements, the paper will not be stretched, and the printing work cannot be implemented. In addition, this might cause wrinkles on the paper. By contrast, if the web tension is excessive, the paper might be broken and create a crack. Several parameters that will impact the web tension are the speed and the angle of rotation. If the speed is too slow, the working time takes longer, consuming more energy. On the contrary, the fast speed will cause the very high kinetic energy which might damage the systems. If the accuracy of the angle of rotation is not sufficient, printing errors will occur. Therefore, in order to maintain the stability of the system, the web tension, the speed and the angle of rotation have to track the reference values with short transient time and small overshoot. 


\section{Backstepping Controller Design}

\subsection{Backstepping Controller Design of Rewinding System}

The rewidening role is to control the web position, the system with backstepping control structure (BSC) of rewinder is demonstrated in Fig. 3. A backstepping control strategy to control the position of roll, each step includes the dynamics of the previous subsystems for backstepping technique:

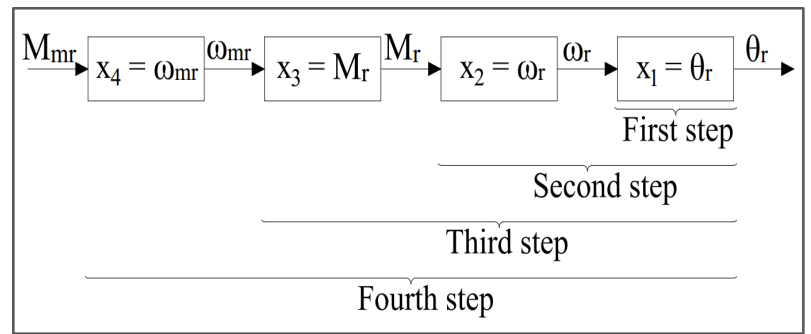

Figure 3. Backstepping control structure for the rewinder

The main objective of this step is to design the control law to ensure position tracking performance in the face of flexible couplings. The following equations are derived according to the step- by-step fashion in formulating the BSC of the system. This can be written by the set of equations as follows [8].

$$
\left\{\begin{array}{l}
\frac{d \theta_{r}}{d t}=\omega_{r} \\
\dot{\omega}_{r}=\left(-\frac{R_{r}}{J_{r}} T-\frac{c_{r}}{J_{r}} \omega_{r}\right)+\frac{1}{J_{r}} M_{r} \\
\dot{M}_{r}=\left[-k_{s r} \omega_{r}+c_{s r}\left(\dot{\omega}_{m r}-\dot{\omega}_{r}\right)\right]+k_{s r} \omega_{m r} \\
\dot{\omega}_{m r}=\left(-\frac{1}{J_{m r}} M_{r}-\frac{c_{m r}}{J_{m r}} \omega_{m r}\right)+\frac{1}{J_{m r}} M_{m r}
\end{array}\right.
$$

Based on a virtual control laws derived in each step for the rewinding system, the equations (14) can be rewritten as follows:

$$
\left\{\begin{array}{l}
\dot{\omega}_{r}^{*}=-c_{1}\left(\theta_{r}-\theta_{s p}\right) \\
M_{r}^{*}=J_{r}\left(-c_{2}\left(\omega_{r}-\omega_{r}^{*}\right)+\frac{R_{r}}{J_{r}} T+\frac{c_{r}}{J_{r}} \omega_{r}\right. \\
\left.+\dot{\omega}_{r}^{*}-\frac{1}{b_{2}}\left(\theta_{r}-\theta_{s p}\right)\right) \\
\omega_{m r}^{*}=\frac{1}{k_{s r}}\left(-c_{3}\left(M_{r}-M_{r}^{*}\right)+k_{s r} \omega_{r}\right. \\
\left.-c_{s r}\left(\dot{\omega}_{m r}-\dot{\omega}_{r}\right)+\dot{M}_{r}^{*}-\frac{1}{b_{3} J_{r}}\left(\omega_{r}-\omega_{r}^{*}\right)\right) \\
M_{m r}^{*}=J_{m r}\left(-c_{4}\left(\dot{\omega}_{m r}-\dot{\omega}_{r}\right)+\frac{1}{J_{m r}} M_{r}\right. \\
\left.+\frac{c_{m r}}{J_{m r}} \omega_{m r}+\dot{\omega}_{m r}-\frac{k_{s r}}{b_{4}}\left(M_{r}-M_{r}^{*}\right)\right)
\end{array}\right.
$$

In the case that $\omega_{r}^{*}=-c_{1}\left(\Theta_{r}-\Theta_{s p}\right)<\omega_{r s p}$, control functions for rewinding system can be written as follows:

$$
\begin{gathered}
\dot{\omega}_{r}^{*}=-c_{1} \omega_{r} ; \ddot{\omega}_{r}^{*}=-c_{1} \dot{\omega}_{r} ; \dddot{\omega}_{r}^{*}=-c_{1} \ddot{\omega}_{r} \\
M_{r}^{*}=J_{r}\left[\begin{array}{l}
-c_{2}\left(\omega_{r}-\omega_{r}^{*}\right)+\frac{R_{r}}{J_{r}} T+\frac{c_{r}}{J_{r}} \omega_{r} \\
+\dot{\omega}_{r}^{*}-\frac{1}{b_{2}}\left(\theta_{r}-\theta_{s p}\right)
\end{array}\right] \\
\dot{M}_{r}^{*}=J_{r}\left[\begin{array}{l}
-c_{2}\left(\dot{\omega}_{r}-\dot{\omega}_{r}^{*}\right)+\frac{R_{r}}{J_{r}} \dot{T}+\frac{c_{r}}{J_{r}} \dot{\omega}_{r} \\
+\ddot{\omega}_{r}^{*}-\frac{1}{b_{2}} \omega_{r}
\end{array}\right] \\
\ddot{M}_{r}^{*}=J_{r}\left(-c_{2}\left(\ddot{\omega}_{r}-\ddot{\omega}_{r}^{*}\right)+\frac{R_{r}}{J_{r}} \dot{T}+\frac{c_{r}}{J_{r}} \ddot{\omega}_{r}[0,1]\right. \\
\left.+\dddot{\omega}_{r}^{*}-\frac{1}{b_{2}} \dot{\omega}_{r}\right) \\
\dot{\omega}_{m r}^{*}=\frac{1}{k_{s r}}\left(-c_{3}\left(\dot{M}_{r}-\dot{M}_{r}^{*}\right)+k_{s r} \dot{\omega}_{r}\right. \\
\left.-c_{s r}\left(\ddot{\omega}_{m r}-\ddot{\omega}_{r}\right)+\ddot{M}_{r}^{*}-\frac{1}{b_{3} J_{r}}\left(\dot{\omega}_{r}-\dot{\omega}_{r}^{*}\right)\right)
\end{gathered}
$$




$$
\begin{aligned}
& M_{m r}^{*}=J_{m r}\left(-c_{4}\left(\dot{\omega}_{m r}-\dot{\omega}_{r}\right)+\frac{1}{J_{m r}} M_{r}\right. \\
& \left.+\frac{c_{m r}}{J_{m r}} \omega_{m r}+\dot{\omega}_{m r}-\frac{k_{s r}}{b_{4}}\left(M_{r}-M_{r}^{*}\right)\right)
\end{aligned}
$$

In the case that $\omega_{r}^{*}=-c_{1}\left(\theta_{r}-\theta_{s p}\right)>\omega_{r s p}$, control laws for rewinding system can be derived as follows:

$$
\begin{gathered}
M_{r}^{*}=J_{r}\left[-c_{2}\left(\omega_{r}-\omega_{r s p}\right)+\frac{R_{r}}{J_{r}} T+\frac{c_{r}}{J_{r}} \omega_{r}\right] \\
\dot{M}_{r}^{*}=J_{r}\left(-c_{2} \dot{\omega}_{r}+\frac{R_{r}}{J_{r}} \dot{T}+\frac{c_{r}}{J_{r}} \dot{\omega}_{r}\right) \\
\ddot{M}_{r}^{*}=J_{r}\left(-c_{2} \ddot{\omega}_{r}+\frac{R_{r}}{J_{r}} \ddot{T}_{r} \frac{c_{r}}{J_{r}} \ddot{\omega}_{r}\right) \\
\omega_{m r}^{*}=\frac{1}{k_{s r}}\left(-c_{3}\left(M_{r}-M_{r}^{*}\right)+k_{s r} \omega_{r}\right. \\
\left.-c_{s r}\left(\dot{\omega}_{m r}-\dot{\omega}_{r}\right)+\dot{M}_{r}^{*}-\frac{1}{b_{3} J_{r}}\left(\omega_{r}-\omega_{r}^{*}\right)\right) \\
\dot{\omega}_{m r}^{*}=\frac{1}{k_{s r}}\left(-c_{3}\left(\dot{M}_{r}-\dot{M}_{r}^{*}\right)+k_{s r} \dot{\omega}_{r}\right. \\
\left.-c_{s r}\left(\ddot{\omega}_{m r}-\ddot{\omega}_{r}\right)+\ddot{M}_{r}^{*}-\frac{1}{b_{3} J_{r}}\left(\dot{\omega}_{r}-\dot{\omega}_{r}^{*}\right)\right) \\
M_{m r}^{*}=J_{m r}\left(-c_{4}\left(\dot{\omega}_{m r}-\dot{\omega}_{r}\right)+\frac{1}{J_{m r}} M_{r}\right. \\
\left.J_{m r}+\dot{\omega}_{m r}-\frac{k_{s r}}{b_{4}}\left(M_{r}-M_{r}^{*}\right)\right)
\end{gathered}
$$

Where $c_{1}, c_{2}, c_{3}, c_{4}$ are the positive gains.

\subsection{Backstepping Controller Design of Unwinding System}

Different from rewinding section, the unwinding roll is in charge of tension regulation. A BSC strategy to control the web position of the R2R, BSC applied to the unwinder is illustrated in Fig. 4

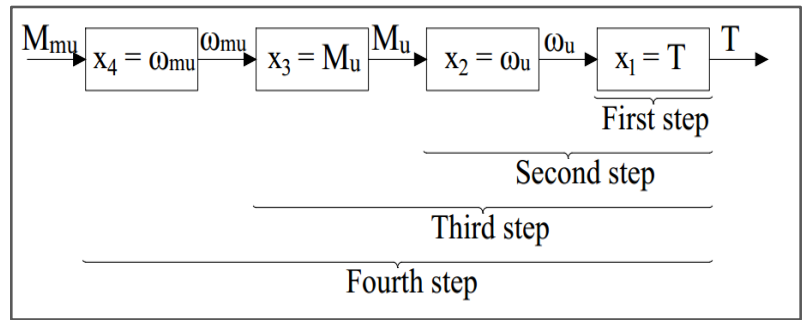

Figure 4. Backstepping control structure for the unwinder

According to the control steps in Fig. 4, the following equations are derived as

$$
\left\{\begin{array}{l}
\dot{T}=\frac{(T+E S) R_{r}}{L} \omega_{r}-\frac{(2 T+E S) R_{u}}{L} \omega_{u} \\
\dot{\omega}_{u}=\left(\frac{R_{u}}{J_{u}} T-\frac{C_{u}}{J_{u}} \omega_{u}\right)+\frac{1}{J_{u}} M_{u} \\
\dot{M}_{u}=\left[-k_{s u} \omega_{u}+c_{s u}\left(\dot{\omega}_{m u}-\dot{\omega}_{u}\right)\right]+k_{s u} \omega_{m u} \\
\dot{\omega}_{m u}=\left(-\frac{1}{J_{m u}} M_{u}-\frac{c_{m u}}{J_{m u}} \omega_{m u}\right)+\frac{1}{J_{m u}} M_{m u}
\end{array}\right.
$$

For the unwinding system, the equations (14) can be given as follows:

$$
\begin{aligned}
& \omega_{u}^{*}=-\frac{L}{(2 T+E S) R_{u}}\left[-c_{5}\left(T-T_{s p}\right)-\frac{(T+E S) R_{r}}{L} \omega_{r}\right] \\
& M_{u}^{*}=J_{u}\left[\begin{array}{l}
c_{6}\left(\omega_{u}-\omega_{u}^{*}\right)-\frac{R_{u}}{J_{u}} T+\frac{c_{u}}{J_{u}} \omega_{u} \\
+\dot{\omega}_{u}^{*}+\frac{(2 T+E S) R_{u}}{L b_{6}}\left(T-T_{s p}\right)
\end{array}\right] \\
& \left\{\omega_{m u}^{*}=\frac{1}{k_{s u}}\left[\begin{array}{l}
-c_{7}\left(M_{u}-M_{u}^{*}\right)+k_{s u} \omega_{u} \\
-c_{s u}\left(\dot{\omega}_{m u}-\dot{\omega}_{u}\right)+\dot{M}_{u}^{*}-\frac{1}{b_{7} J_{u}}\left(\omega_{u}-\omega_{u}^{*}\right)
\end{array}\right]\right. \\
& M_{m u}^{*}=J_{m u}\left[\begin{array}{l}
-c_{8}\left(\dot{\omega}_{m u}-\dot{\omega}_{u}\right)+\frac{1}{J_{m u}} M_{u}+ \\
\frac{c_{m u}}{J_{m u}} \omega_{m u}+\dot{\omega}_{m u}^{*}-\frac{k_{s u}}{b_{8}}\left(M_{u}-M_{u}^{*}\right)
\end{array}\right]
\end{aligned}
$$

Where:

$$
\dot{M}_{u}^{*}=J_{u}\left[\begin{array}{c}
-c_{6}\left(\dot{\omega}_{u}-\dot{\omega}_{u}^{*}\right)-\frac{R_{u}}{J_{u}} \dot{T}+\frac{c_{u}}{J_{u}} \dot{\omega}_{u} \\
+\ddot{\omega}_{u}^{*}+\frac{\left(4 T+E S-2 \mathrm{~T}_{s p}\right) \dot{T} R_{u}}{L b_{6}}
\end{array}\right]
$$

$$
\ddot{M}_{u}^{*}=J_{u}\left(\begin{array}{c}
-c_{6}\left(\ddot{\omega}_{u}-\ddot{\omega}_{u}^{*}\right)-\frac{R_{u}}{J_{u}} \ddot{T}+\frac{c_{u}}{J_{u}} \ddot{\omega}_{u}+\dddot{\omega}_{u}^{*} \\
+\frac{\left[\left(4 T+E S-2 T_{s p}\right) \ddot{T}+4 \dot{T}^{2}\right] R_{u}}{L b_{6}}
\end{array}\right)
$$

$\dot{\omega}_{m u}^{*}=\frac{1}{k_{s u}}\left[\begin{array}{l}-c_{7}\left(\dot{\mathrm{M}}_{u}-\dot{\mathrm{M}}_{u}^{*}\right)+k_{s u} \dot{\omega}_{u} \\ -c_{s u}\left(\ddot{\omega}_{m u}-\ddot{\omega}_{u}\right)+\ddot{\mathrm{M}}_{u}^{*}-\frac{1}{b_{7} J_{u}}\left(\dot{\omega}_{u}-\dot{\omega}_{u}^{*}\right)\end{array}\right]$

$$
\dot{\omega}_{u}^{*}=-\frac{L}{(2 T+E S) R_{u}}\left[-c_{5} \dot{T}-\frac{(T+E S) R_{r}}{L} \dot{\omega}_{r}\right]
$$

$\ddot{\omega}_{u}^{*}=-\frac{L}{(2 T+E S) R_{u}}\left[-c_{5} \ddot{T}-\frac{(T+E S) R_{r}}{L} \ddot{\omega}_{r}\right]$

$$
\dddot{\omega}_{u}^{*}=-\frac{L}{(2 T+E S) R_{u}}\left[-c_{5} \dddot{T}-\frac{(T+E S) R_{r}}{L} \dddot{\omega}_{r}\right]
$$

Where $c_{5}, c_{6}, c_{7}, c_{8}$ are the positive gains 


\subsection{Determination of Optimal Controller Parameters}

For the same class, parameters $\mathrm{b}$ and $\mathrm{c}$ can be chosen as follows: $b_{2}=16, \quad b_{3}=4.10^{-6}, \quad b_{4}=2,5.10^{5}$, $b_{5}=9.10^{7}, b_{6}=4.94 \times 10^{-6}, b_{7}=2.3 \times 10^{10}, c_{1}=8$, $c_{2}=60, c_{3}=101, c_{4}=137, \quad c_{5}=29, \quad c_{6}=128$, $c_{7}=157, c_{8}=195$. Where $c_{1}, c_{2}, c_{3}, c_{4}, c_{5}, c_{6}$, $c_{7}, c_{8}$ are the positive gains and determined by the modified genetic algorithm [16].

\section{Simulation Results}

The simulation reference values of the rewinding control system are shown in Table 3.

The goal is to design the precise control algorithm and BSC that is required to keep the web tension, rotational angular and angular velocity at prescribed reference values, to satisfy the performance specifications and to obtain the high stability.
Table 3. Simulation parameters

\begin{tabular}{|c|c|c|}
\hline Parameters & Values & Units \\
\hline The width of web & 1 & $\mathrm{~m}$ \\
\hline The thickness of web & 0.0002 & $\mathrm{~m}$ \\
\hline Total length of web & 8 & $\mathrm{~m}$ \\
\hline Elasticity of web & $2,5 \cdot 10^{9}$ & $\mathrm{~N} / \mathrm{m}^{2}$ \\
\hline Operating radius of the unwind roll & 1,5 & $\mathrm{~m}$ \\
\hline Operating radius of the rewind roll & 0,5 & $\mathrm{~m}$ \\
\hline $\begin{array}{l}\text { Total moment of inertia of the unwind } \\
\text { roll }\end{array}$ & 6400 & $\mathrm{Kgm}^{2}$ \\
\hline Total moment of inertia of the rewind roll & 160 & Kg. $\mathrm{m}^{2}$ \\
\hline $\begin{array}{l}\text { Coefficient of vicious friction of the } \\
\text { unwind roll }\end{array}$ & 1 & $\mathrm{Nms}$ \\
\hline $\begin{array}{l}\text { Coefficient of vicious friction of the } \\
\text { rewind roll }\end{array}$ & 50 & $\mathrm{Nms}$ \\
\hline Shaft stiffness of the unwind motor & $10^{6}$ & $\mathrm{Nm}$ \\
\hline Shaft stiffness of the rewind motor & $10^{6}$ & $\mathrm{Nm}$ \\
\hline
\end{tabular}

In order to test the proposed algorithm in the operating condition of the model R2R with flexible couplings. The change of angular of the rewind roll is assumed in the Fig.5 corresponding to the web speed position.

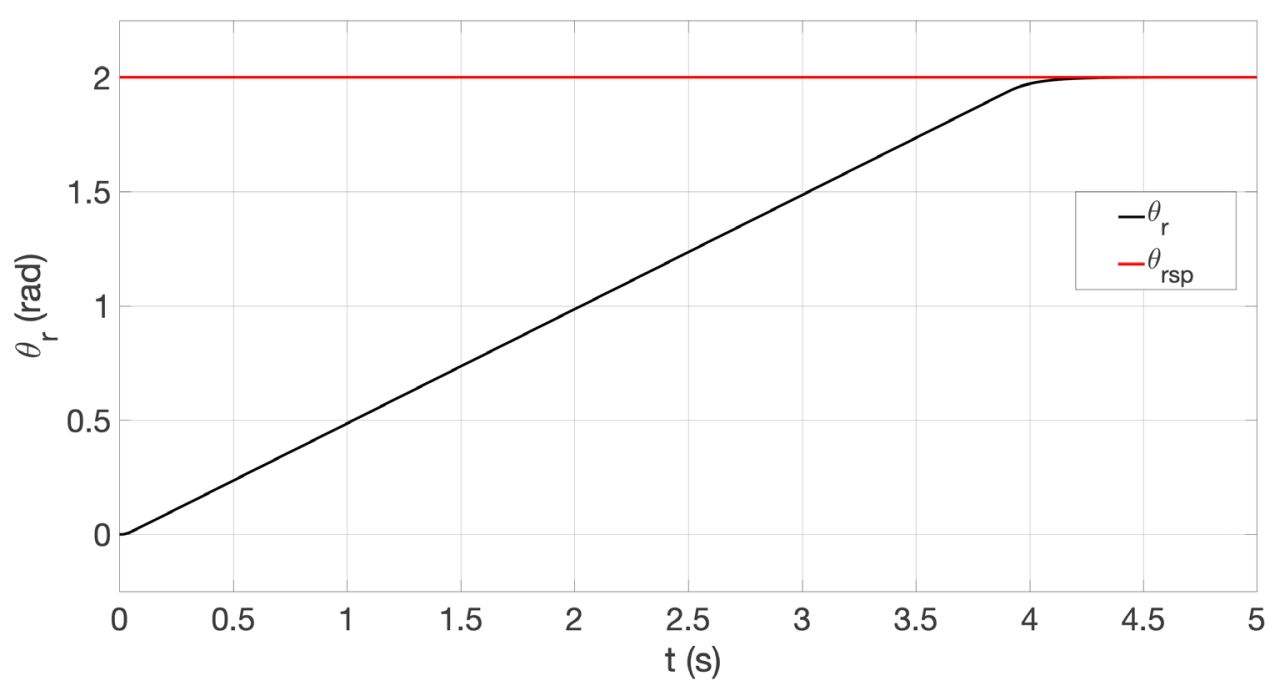

Figure 5. Angular response of the rewind roll 


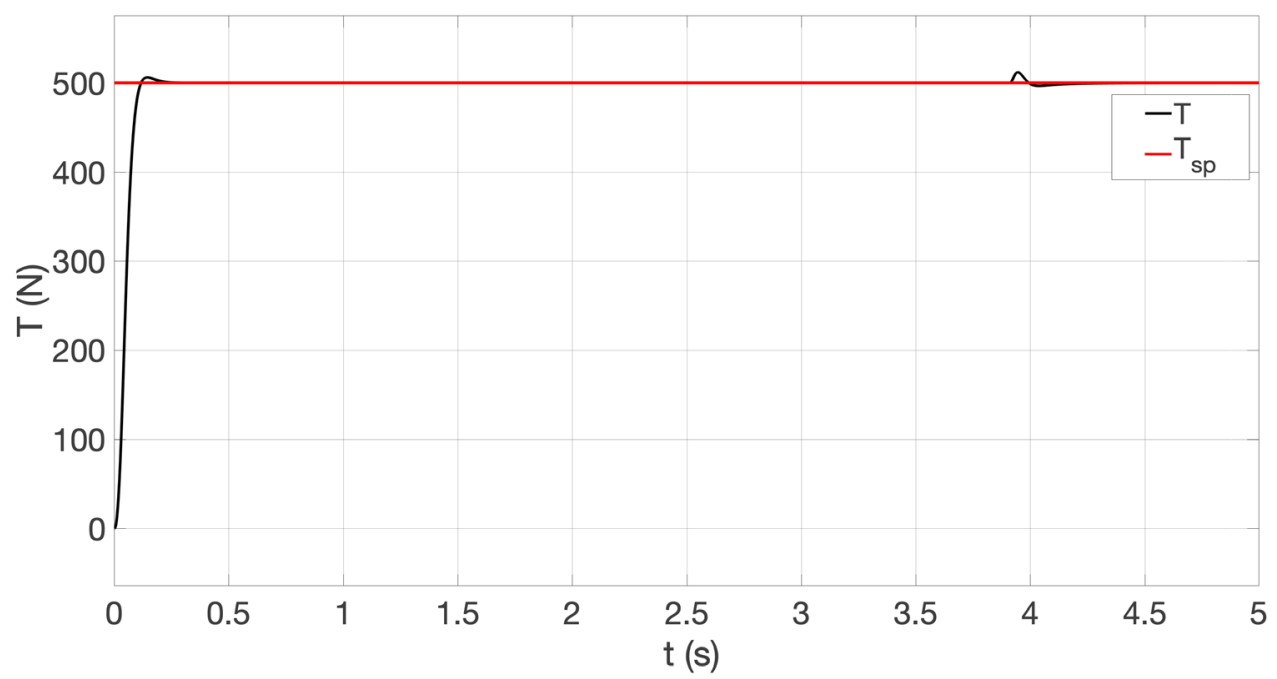

Figure 6. Web tension response

Fig. 6 shows the tracking performance of the web tension, in which the time response of web tension with BSC yields the peak overshoot of $1,2 \%$ and the fast response with settling time of $0.15 \mathrm{~s}$. Although the overshoot of $2,4 \%$ is observed again during the deceleration, it is still in an acceptable range

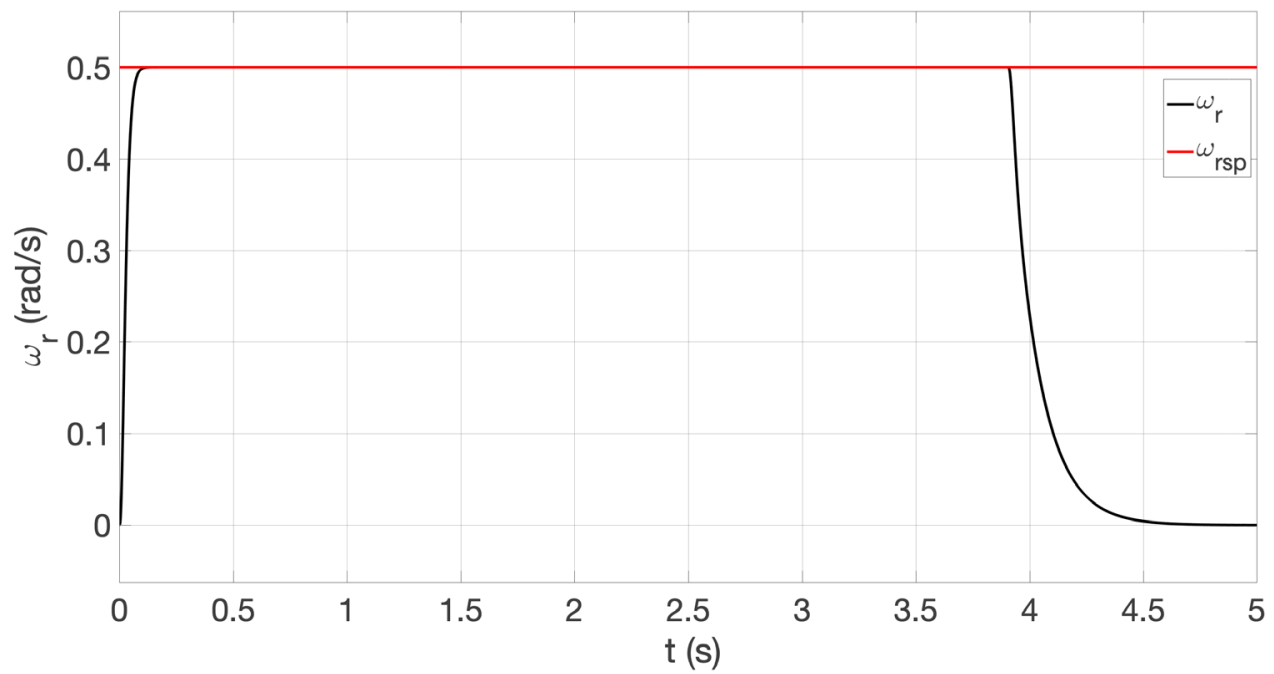

Figure 7. Rotational angular response of the rewind roll

By contrast, it can be seen from Fig. 7 that the angular speed of unwinding and rewinding section is kept stable at the reference value without overshoot with respect to the position reference of the web. 


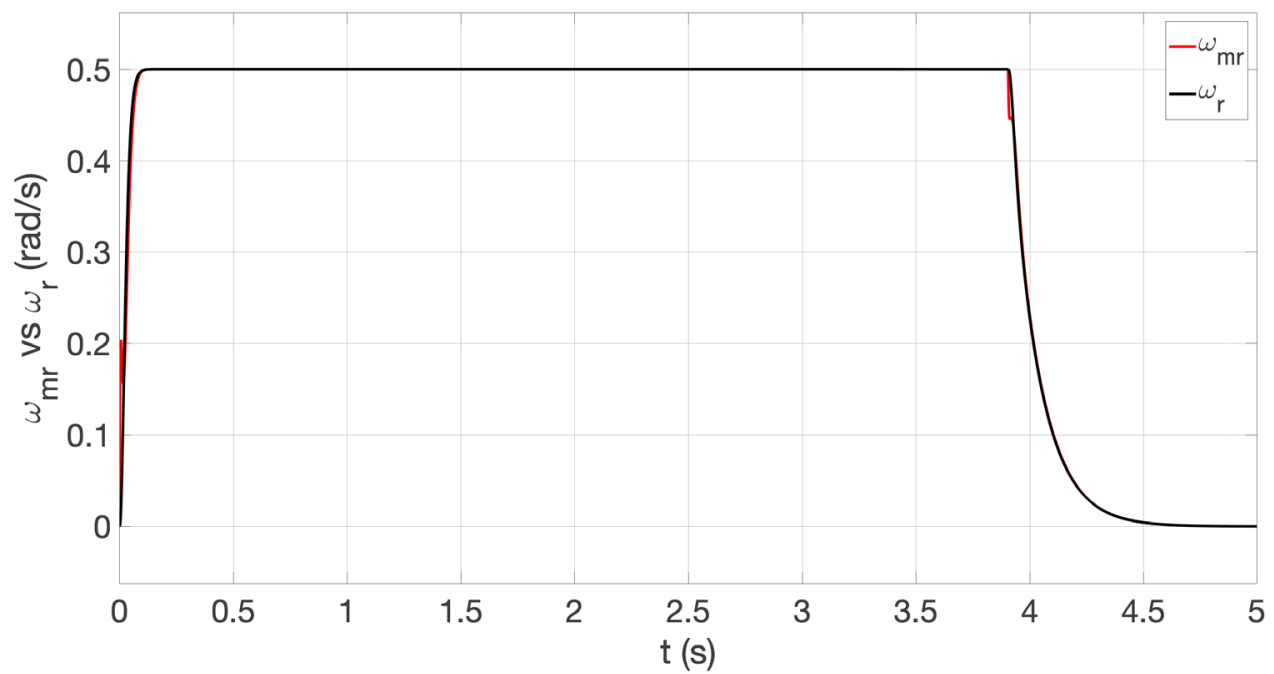

Figure 8. Rotational angular responses of the rewind motor and the rewind roll

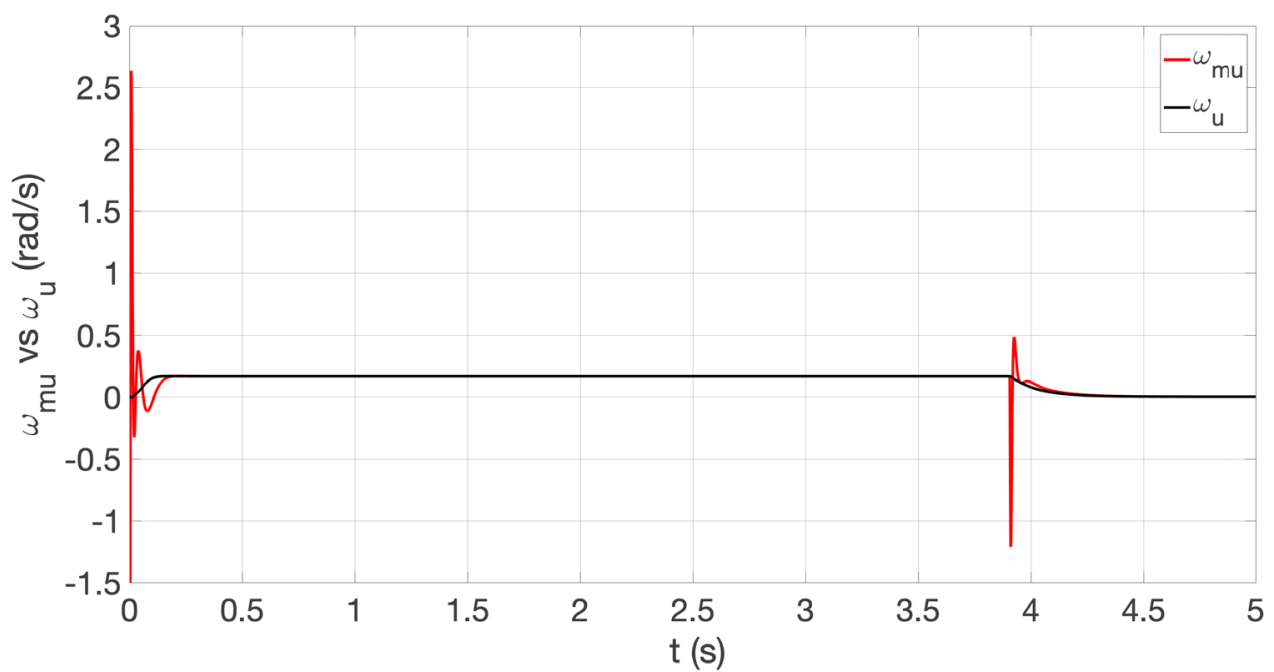

Figure 9. Rotational angular responses of the unwind motor and the unwind roll.

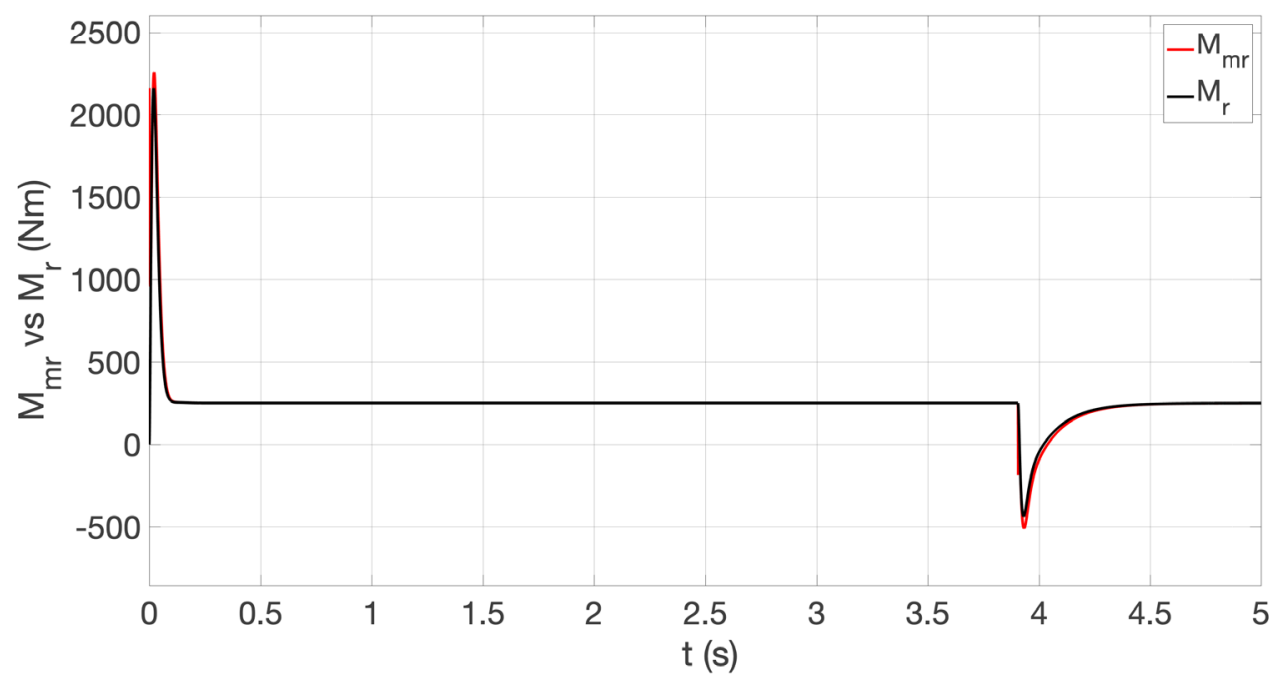

Figure 10. Torque responses of the rewind motor and the rewind roll. 


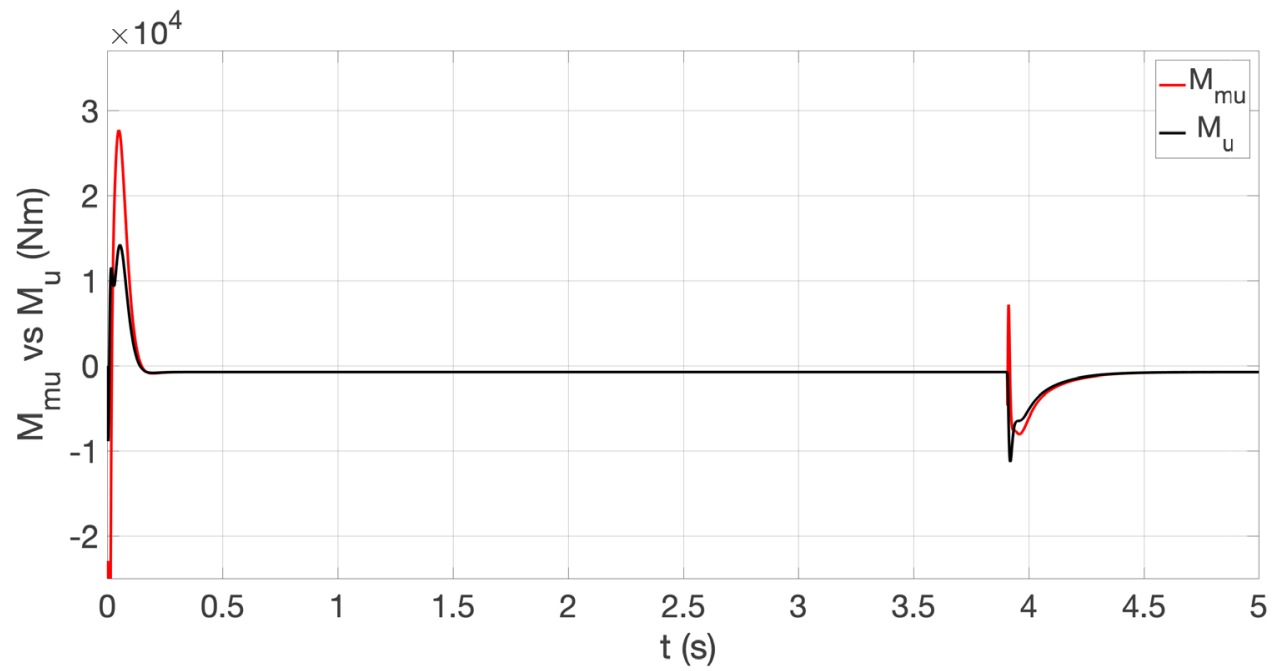

Figure 11. Torque responses of the unwind motor and the unwind roll.

Fig. 8 and 9 indicate the angular speed at motor and rewinding-unwinding rolls sides. The speed difference in between the two sides show the effects of the flexible couplings on the system. The flexibility again is clearly demonstrated in viewing applied torques on motor and rolls as can be seen in Figure 10 and 11. The difference in speed and torque responses is eliminated with the system possessing rigid couplings.

\section{Conclusions}

In this paper, the mathematical model of the roll to roll system by taking flexible couplings into account has been systematically developed. The control of position and tension of the moving web have been considered to enhance the production quality of the system. Notice that the backstepping controller was proposed for the control algorithm of the attained model and verification of the proposed control strategy was examined by simulation results. The results show that the precision and the stability of the system were achieved with high dynamics performance and negligible overshoots.

\section{Acknowledgements}

This research is supported by Hanoi University of Science and Technology research grant T2018-PC-053.

\section{REFERENCES}

[1] X. M. Xu, W. X. Zhang, X. L. Ding, M. Zhang, and S. H. Wei, "Design and Analysis of a Novel Tension Control Method for Winding Machine," Chinese J. Mech. Eng. (English Ed., vol. 31, no. 1, 2018.
[2] K. H. Choi et al., "Web register control algorithm for roll-to-roll system based printed electronics," 2010 IEEE Int. Conf. Autom. Sci. Eng. CASE 2010, pp. 867-872, 2010.

[3] S. T. Giannoccaro. N.I, Oishi. K, "an Experimental Web Tension Control System : System Set-Up," Adv. Prod. Eng. Manag., vol. 2, no. 4, pp. 185-193, 2007.

[4] A. Kulachenko, "Mechanics of Paper Webs in Printing Press," no. 62, 2006

[5] D. E. Chang, J. Levine, J. Jo, and K. H. Choi, "Control of roll-to-roll web systems via differential flatness and dynamic feedback linearization," IEEE Trans. Control Syst. Technol., vol. 21, no. 4, pp. 1309-1317, 2013.

[6] "Design and implementation of adaptive PI control schemes for web tension control in roll-to-roll (R2R) manufacturing.pdf." .

[7] J. K. Chen, Z. P. Yin, Y. L. Xiong, and J. Z. Quan, “A hybrid control method of tension and position for a discontinuous web transport system," 2009 IEEE Int. Conf. Inf. Autom. ICIA 2009, no. 2003, pp. 265-270, 2009.

[8] T. Nishida, T. Sakamoto, and N. I. Giannoccaro, "Self-tuning PI control using adaptive PSO of a web transport system with overlapping decentralized control," Electr. Eng. Japan (English Transl. Denki Gakkai Ronbunshi), vol. 184, no. 1, pp. 56-65, 2013.

[9] K. H. Choi, T. T. Thanh, and D. S. Kim, "A precise control algorithm for single-span roll-to-roll web system using the back-stepping controller," IEEE Int. Symp. Ind. Electron., no. ISIE, pp. 1709-1714, 2009.

[10] K. C. Lin, M. C. Tsai, and K. Y. Chen, "Web tension control of a start-up process using observer techniques with friction and inertia compensation," IECON Proc. (Industrial Electron. Conf., vol. 3, no. C, pp. 529-534, 2001.

[11] T. T. Tran and K. H. Choi, "A backstepping-based control algorithm for multi-span roll-to-roll web system," Int. J. Adv. Manuf. Technol., vol. 70, no. 1-4, pp. 45-61, 2014.

[12] B. Bouchiba, A. Hazzab, H. Glaoui, F. Med-Karim, I. K. Bousserhane, and P. Sicard, "Backstepping control for multi-machine web winding system," J. Electr. Eng. 
Technol., vol. 6, no. 1, pp. 59-66, 2011.

[13] C. L. Chen, K. M. Chang, and C. M. Chang, "Modeling and control of a web-fed machine," Appl. Math. Model., vol. 28, no. 10, pp. 863-876, 2004.

[14] T. Sakamoto and Y. Fujino, "Modelling and analysis of a web tension control system," IEEE Int. Symp. Ind. Electron., vol. 1, pp. 358-362, 1995.

[15] K. H. Shin, J. I. Jang, H. K. Kang, and S. H. Song, "Compensation method for tension disturbance due to an unknown roll shape in a web transport system," IEEE Trans. Ind. Appl., vol. 39, no. 5, pp. 1422-1428, 2003.

[16] K. H. Choi, T. T. Tran, and D. S. Kim, "Back-stepping controller based web tension control for roll-to-roll web printed electronics system," J. Adv. Mech. Des. Syst. Manuf., vol. 5, no. 1, pp. 7-21, 2011.

[17] T. T. TRAN, K.-H. CHOI, D.-E. CHANG, and D.-S. KIM, "Web Tension and Velocity Control of Two-Span Roll-to-Roll System for Printed Electronics," J. Adv. Mech. Des. Syst. Manuf., vol. 5, no. 4, pp. 329-346, 2011.

[18] C. G. Kang and B. J. Lee, "Stability analysis for design parameters of a roll-to-roll printing machine," ICCAS 2007 - Int. Conf. Control. Autom. Syst., pp. 1460-1465, 2007.

[19] C. W. Cheng, C. H. Hsiao, C. C. Chuang, K. C. Chen, and W. P. Tseng, "Observer-based tension feedback control of direct drive web transport system," in Proceedings of the 2005 IEEE International Conference on Mechatronics, ICM '05, 2005, vol. 2005, pp. 745-750.

[20] C. N. Manh, M. T. Van, D. N. Duc, L. N. Tung, D. P. Tien, and L. T. Thi, "Neural network based adaptive control of web transport systems," in Proceedings of 2019 International Conference on System Science and Engineering, ICSSE 2019, 2019, pp. 124-128.

[21] H. Conduction, D. E.- General, and O. H. E.- Consider, "Experimental Reseach on Decoupling Control of Multi-motor Variable Frequency System Based on Neural Network Generalized Inverse," vol. 4, pp. 1-14, 2011.

[22] L. V. Meetei, B. A. Shimray, and R. Malemnganbi, "Vibration Suppression of a 2-Mass Drive System with Multiple Feedbacks," vol. 5, no. 11, pp. 168-175, 2015. 